\title{
Factors shaping the COVID-19 epidemic curve: a multi-country analysis
}

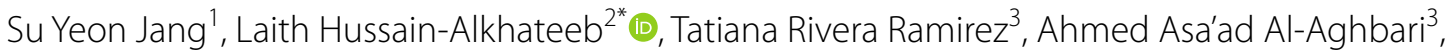 \\ Dhia Joseph Chackalackal ${ }^{3}$, Rocio Cardenas-Sanchez ${ }^{3,4}$, Maria Angelica Carrillo ${ }^{3,5}$, In-Hwan Oh', \\ Eduardo Andrés Alfonso-Sierra ${ }^{3}$, Pia Oechsner ${ }^{6}$, Brian Kibiwott Kirui ${ }^{2}$, Martin Anto ${ }^{7}$, Sonia Diaz-Monsalve ${ }^{3}$ and \\ Axel Kroeger ${ }^{3^{*}}$
}

\begin{abstract}
Background: Lockdown measures are the backbone of containment measures for the COVID-19 pandemic both in high-income countries (HICS) and low- and middle-income countries (LMICS). However, in view of the inevitablyoccurring second and third global covid-19 wave, assessing the success and impact of containment measures on the epidemic curve of COVID-19 and people's compliance with such measures is crucial for more effective policies. To determine the containment measures influencing the COVID-19 epidemic curve in nine targeted countries across high-, middle-, and low-income nations.
\end{abstract}

Methods: Four HICs (Germany, Sweden, Italy, and South Korea) and five LMICs (Mexico, Colombia, India, Nigeria, and Nepal) were selected to assess the association using interrupted time series analysis of daily case numbers and deaths of COVID-19 considering the following factors: The "stringency index (SI)" indicating how tight the containment measures were implemented in each country; and the level of compliance with the prescribed measures using human mobility data. Additionally, a scoping review was conducted to contextualize the findings.

Results: Most countries implemented quite rigorous lockdown measures, particularly the LMICs (India, Nepal, and Colombia) following the model of HICs (Germany and Italy). Exceptions were Sweden and South Korea, which opted for different strategies. The compliance with the restrictions-measured as mobility related to home office, restraining from leisure activities, non-use of local transport and others-was generally good, except in Sweden and South Korea where the restrictions were limited. The endemic curves and time-series analysis showed that the containment measures were successful in HICs but not in LMICs.

Conclusion: The imposed lockdown measures are alarming, particularly in resource-constrained settings where such measures are independent of the population segment, which drives the virus transmission. Methods for examining people's movements or hardships that are caused by covid- no work, no food situation are inequitable. Novel and context-adapted approach of dealing with the COVID-19 crisis are therefore crucial.

\footnotetext{
*Correspondence: laith.hussain@gu.se; kroegera43@gmail.com

${ }^{2}$ Global Health, School of Public Health and Community Medicine,

Institute of Medicine, University of Gothenburg, Medicinaregatan 18A,

41390 Gothenburg, Sweden

${ }^{3}$ Centre for Medicine and Society, Albert-Ludwigs-University Freiburg,

Bismarckallee (3'd floor), 79089 Freiburg, Germany

Full list of author information is available at the end of the article
}

(C) The Author(s) 2021. Open Access This article is licensed under a Creative Commons Attribution 4.0 International License, which permits use, sharing, adaptation, distribution and reproduction in any medium or format, as long as you give appropriate credit to the original author(s) and the source, provide a link to the Creative Commons licence, and indicate if changes were made. The images or other third party material in this article are included in the article's Creative Commons licence, unless indicated otherwise in a credit line to the material. If material is not included in the article's Creative Commons licence and your intended use is not permitted by statutory regulation or exceeds the permitted use, you will need to obtain permission directly from the copyright holder. To view a copy of this licence, visit http://creativecommons.org/licenses/by/4.0/. The Creative Commons Public Domain Dedication waiver (http://creativeco mmons.org/publicdomain/zero/1.0/) applies to the data made available in this article, unless otherwise stated in a credit line to the data. 
Keywords: Coronavirus disease 2019, SARS-CoV-2, Segemented Time-series, Lockdown, COVID-19, Stringency index, Human mobility

\section{Background}

Soon after the start of the COVID-19 pandemic in China, many countries followed the Chinese example to put emphasis on transmission control through quarantine of infected persons, the isolation of contacts, and then the lockdown of the entire population [1, 2]. The theoretical background was based on a mathematical prediction model about the expected epidemic curve showing that without transmission control, the curve would be very high and stiff but with "non-pharmaceutical interventions (NPIs)", it would be prolonged but with lower case numbers and thus manageable by the health services [3]. Strict lockdown measures were particularly undertaken in the high-income countries (HICs) of Europe and then carried forward by low-and middle-income countries (LMICs), often leading to economic recession, human suffering and public unrest due to job and income loss $[4,5]$. However, there were some different approaches with less stringent lockdown policies such as in Sweden and South Korea [6]. This provides an opportunity to analyse counter-measures and the level of compliance to such measures leading to the highest impact on the shape of the epidemic curve, five months after the start of the pandemic. Additionally, it enables to investigate if the real-life experience in different countries confirms the previously defined prediction model [3], and intends to show "when" and "how much" containment measures are successful in low and high income countries which will help to take up evidence based policy decision according to the local context.

\section{Methods \\ Study countries}

Four HICs (Germany, Sweden, Italy, and South Korea), two better-off MICs (Mexico and Colombia), and three LICs with lower economic power (India, Nigeria, and Nepal) were selected in order to reflect the measures and impact of the covid-19 pandemic in countries with different levels of wealth, size and population densities. Academic contacts in these countries facilitated the data collection. Table 1 shows that large (India, Nigeria, and Mexico) and small countries (Sweden and Nepal) with high (South Korea and India) and low population densities (Sweden and Colombia) were included. The percentage of children within the total population was less in countries with a high Human Development Index (European countries and South Korea) and more if the index was lower (Nigeria, Nepal, and India). Table 2 shows that countries with a high Gross Domestic Product (GDP) have a low informal economic sector and the LMICs have a high proportion of "self-employed" or "vulnerable employment" who will suffer most by the lockdown measures. The only exception was South Korea, with a high GDP but yet a considerable informal economic sector, due to its recent history of moving from a LMIC to a HIC.

\section{Scoping review of the literature}

To complement our findings, a scoping review of the scientific literature was conducted with the following question: "What measures can influence the COVID19 epidemic curve among the nine targeted countries?" The scoping review, as an ideal approach to determine

Table 1 Demographic, geographic, and developmental characteristics of the 9 target countries

\begin{tabular}{|c|c|c|c|c|}
\hline Country & $\begin{array}{l}\text { Total population } \\
\text { (thousands) }\end{array}$ & $\begin{array}{l}\text { Population density (persons } \\
\text { per } \mathrm{km}^{2} \text { ) }\end{array}$ & $\begin{array}{l}\text { Percentage of children } \\
\text { (0-14 year) (\%) }\end{array}$ & $\begin{array}{l}\text { Human } \\
\text { Development } \\
\text { Index (value) }\end{array}$ \\
\hline Germany & 83,517 & 240 & 14 & 0.939 \\
\hline Italy & 60,550 & 206 & 13 & 0.883 \\
\hline Sweden & 10,036 & 25 & 18 & 0.937 \\
\hline South Korea & 51,225 & 527 & 13 & 0.906 \\
\hline Colombia & 50,339 & 45 & 22 & 0.761 \\
\hline Mexico & 127,576 & 66 & 26 & 0.767 \\
\hline Nigeria & 200,964 & 221 & 45 & 0.534 \\
\hline India & $1,366,418$ & 460 & 26 & 0.647 \\
\hline Nepal & 28,609 & 200 & 29 & 0.579 \\
\hline
\end{tabular}

Data Sources: United Nations:World Population Prospects 2019 (online: https://population.un.org/wpp/Download/Standard/Population/); United Nations Development Programme: Human Development Report 2019, p. 304 (online: http://hdr.undp.org/sites/default/files/hdr2019.pdf) 
Table 2 Selected economic indicators of the nine target countries (World Bank, World Development Indicator, 2018)

\begin{tabular}{|c|c|c|c|c|c|c|c|c|c|}
\hline Name & Sweden & Germany & South Korea & Italy & Mexico & Colombia & India & Nigeria & Nepal \\
\hline GDP per capita, PPP (constant 2011 international \$) & 47,718 & 45,936 & 36,777 & 35,828 & 18,134 & 13,321 & 6888 & 5316 & 2741 \\
\hline $\begin{array}{l}\text { Poverty headcount ratio at } \$ 3.20 \text { a day (2011 PPP) (\% } \\
\text { of population) }\end{array}$ & $0.3 \%$ & $0.2 \%$ & $0.5 \%$ & $1.8 \%$ & $6.6 \%$ & $10.9 \%$ & $60.4 \%$ & & $50.9 \%$ \\
\hline $\begin{array}{l}\text { Self-employed, total (\% of total employment) (mod- } \\
\text { eled ILO estimate) }\end{array}$ & $9.6 \%$ & $9.9 \%$ & $25.1 \%$ & $22.9 \%$ & $31.6 \%$ & $51.4 \%$ & $76.5 \%$ & $81.5 \%$ & $79.8 \%$ \\
\hline $\begin{array}{l}\text { Vulnerable employment, total (\% of total employment) } \\
\text { (modeled ILO estimate) }\end{array}$ & $6.1 \%$ & $5.7 \%$ & $19.2 \%$ & $16.8 \%$ & $26.8 \%$ & $47.2 \%$ & $74.5 \%$ & $77.7 \%$ & $78.7 \%$ \\
\hline $\begin{array}{l}\text { Informal employment (\% of total non-agricultural } \\
\text { employment) }\end{array}$ & & & & & & $57.2 \%$ & $80.3 \%$ & & $77.6 \%$ \\
\hline
\end{tabular}

Source: World Development Indicators (WDI), compiled by the World Bank from officially recognized international sources. https://data.worldbank.org/indicator?tab= all

"Employment in the informal economy as a percentage of total non-agricultural employment. It basically includes all jobs in unregistered and/or small-scale private unincorporated enterprises that produce goods or services meant for sale or barter. Self-employed street vendors, taxi drivers and home-base workers, regardless of size, are all considered enterprises. However, agricultural and related activities, households producing goods exclusively for their own use (e.g. subsistence farming, domestic housework, care work, and employment of paid domestic workers), and volunteer services rendered to the community are excluded"

"Self-employed workers are those workers who, working on their own account or with one or a few partners or in cooperative, hold the type of jobs defined as a self-employment job (i.e., jobs where the remuneration is directly dependent upon the profits derived from the goods and services produced). Self-employed workers include four sub-categories of employers, own-account workers, members of producers' cooperatives, and contributing family workers"

"Vulnerable employment is contributing family workers and own-account workers as a percentage of total employment"

"Poverty headcount ratio at $\$ 3.20$ a day is the percentage of the population living on less than $\$ 3.20$ a day at 2011 international prices."

"Proportion of employed people who live on less than $\$ 3.20$ (in purchasing power parity terms) a day, expressed as a percentage of the total employed population ages 15 and older." ILO (2019). ILOSTAT database. www.ilo.org/ilostat

"Percentage of the population at risk of suffering multiple deprivations-that is, those with a deprivation score of 20-33 percent." Source: Human Development Report Office (HDRO) calculations, based on data on household deprivations in health, education, and standard of living from various household surveys. Latest data for Mexico, Colombia, India, Nepal from year 2016, Nigeria year 2017. http://hdr.undp.org/en/indicators/142506

the scope of a body literature on covid-19 while examining emerging evidence in a short period of time, was the prime choice in this study.

On May 9, 2020, a search was conducted in online databases, PubMed and Cochrane library with key search terms such as "COVID-19", "measures", and "factors". The inclusion criteria were scientific articles with information on influencing factors of COVID-19 epidemic curve and public health measures adopted by nine targeted countries. Observational and intervention studies including qualitative, quantitative, or mixed methodologies, as well as scoping reviews and full text papers in English or Spanish language were included. Preprint scientific studies were included due to the urgency of the pandemic. The excluded articles were letters to the editor, opinions, guidelines, commentaries and editorials. The study selection was done independently by three researchers (TRR, MAC, and RCS). The three sets of literature were then compared. Disagreements on the inclusion or exclusion of literature were solved through discussions or by including a fourth researcher (AK). The search was carried out in three stages. First, titles were evaluated according to the inclusion and exclusion criteria. Second, the same criteria were applied to the abstract section of the articles retained in the first stage. Third, full text articles and articles without abstract availability in the previous stages were evaluated. However, after completion of the scoping review, new publications came up which will be presented in the "Discussion" Section.

\section{Data collection and analysis in the nine study countries Measuring number of daily infections and deaths}

Daily numbers of infections and deaths were collected from various existing data sources. Each country's national confirmed and deceased cases were collected through a data hub of COVID-19 datasets [7]. Furthermore, the COVID-19 related situation on a subnational level was analyzed. Targeted regions were: Västra Götaland (Sweden), Lombardy (Italy), BadenWürttemberg (Germany), Daegu (South Korea), Kathmandu (Nepal), Nuevo León (Mexico), Abuja (Nigeria), North Santander (Colombia), and Kerala (India). For European regions, data was obtained from the above mentioned repository [8], however, non-European areas were not accessible through the repository, and thus collected through each country's national or regional official health service websites [9-14]. Rates of infection and deaths per 100,000 population were estimated for all nine countries based on the study period from January-May 2020 and the corresponding midyear population size as the denominator [15]. 


\section{Measuring timing and intensity of the lockdown}

To assess the intensity of lockdown measures in the target countries, the 'Stringency Index' (SI) of the strictness in governmental policies was calculated using eight indicators: closure of schools, workplaces, public events, and/or of public transportation; restrictions on gatherings, internal movements, and international travels; and the quarantine requirements. Computation of the index followed the methodology described by Hale et al., which estimated the intensity of governmental measures into a scale from 1 to 100 , with 100 indicating the maximum application of all indicators mentioned above [16]. The mean (SD) and percentiles (25th, 50th, 75th, and 95th) of the SI were computed for each country and sub-country. Data of government responses in our target countries was collected from the Oxford COVID-19 Government Response Tracker [17].

\section{Measuring peoples ' compliance with the lockdown}

For the documentation of peoples' compliance with the lockdown, data from the Google COVID-19 Community Mobility Reports was used to measure the change in human mobility [18]. In these reports, percentage of changes in visits to different places (i.e., retail and recreation, grocery and pharmacy, parks, transit stations, workplaces, and residential areas) were compared to the baseline level (i.e., the median value from January 3rd to February 6th 2020) and were estimated by aggregating the location data of Google account holders.

\section{Data management and analysis}

\section{Data management of the scoping review}

Data from the included studies in the scoping review were extracted and recorded in an Excel spreadsheet. The following information was collected for each article: Authors of the publication, country, study design, status of the publication, analysed measure (e.g., school closures or the lockdown), methodology, instruments, and results. No formal assessment of the methodological quality of the included articles was performed in this review, however, the quality of the papers was defined by the inclusion and exclusion criteria. Figure 1 shows the selection process of the papers [19]. A total of 1344 papers were initially retrieved. After the application of the inclusion and exclusion criteria, 17 publications were included for the synthesis of the review (Additional file 1). A narrative description is presented in the "Results" Section.

\section{Interrupted time-series analysis}

To better understand the impact of the SI on the incidence and mortality as core outcome variables, an interrupted time-series analysis of mortality and morbidity rates was conducted independently per country and sub-country [20]. The SI is the analysis predictor; in order to transform its continuous format into a meaningful intervention measure before processing the time-series analysis, the median value of SI in each country was defined as "intervention one,". This was based on observations that the SI was able to demonstrate an impact in relation to the baseline values (both the minimum and 25th percentile) at the 50th percentile. A sensitivity analysis was performed to test this assumption; an exception was made for Sweden where the 10th percentile value was used as "intervention one" due to their relatively low stringency measures. Second and third points of interventions were defined based on 75th and 95th percentiles, respectively. In this analysis some countries managed to implement all three interventions, whereas other countries implemented one or two interventions. When two percentiles revealed small differences $(<10 \%)$, the higher percentile was used in the regression. "Baseline trend" refers to the change in rate prior to intervention one; "change at first, second, or third interventions" refers to the change in rate immediately after each intervention; "trend after each intervention" refers to the continuous change in rate after the current intervention and until the next intervention; and the "overall trend after all interventions" refers to the change in rate due to all interventions. These four trends were presented as "rates of change per 100,000 population" together with their $\mathrm{p}$-value at $5 \%$ significant cut-off.

\section{Results}

Dynamics of the COVID-19 pandemic according to the scoping review

Time lag between containment measure, daily slow-down effect, and deaths

A study in Italy demonstrated that the containment measures reduced the progression of the COVID-19 epidemic [21]. The time lag between implementing measures to the reduction of COVID-19 growth rate was approximately 7-10 days. The analysis in different Italian regions showed that the earlier the measures were taken, the lower was the cumulative incidence. The importance of implementing early measures was also observed in 25 European countries: as countries with the highest mortality (Italy, Spain, and France) were late to implement national restrictions. Sweden adopted fewer restrictions compared to other neighbouring countries and suffered a higher mortality rate [22].

\section{Daily growth rate in a controlled and uncontrolled situation}

Various modelling studies analysed different scenarios to control the spread of COVID-19. A study assessed the effectiveness of social distancing in Italy based on the level of adherence to quarantine. They predicted a 


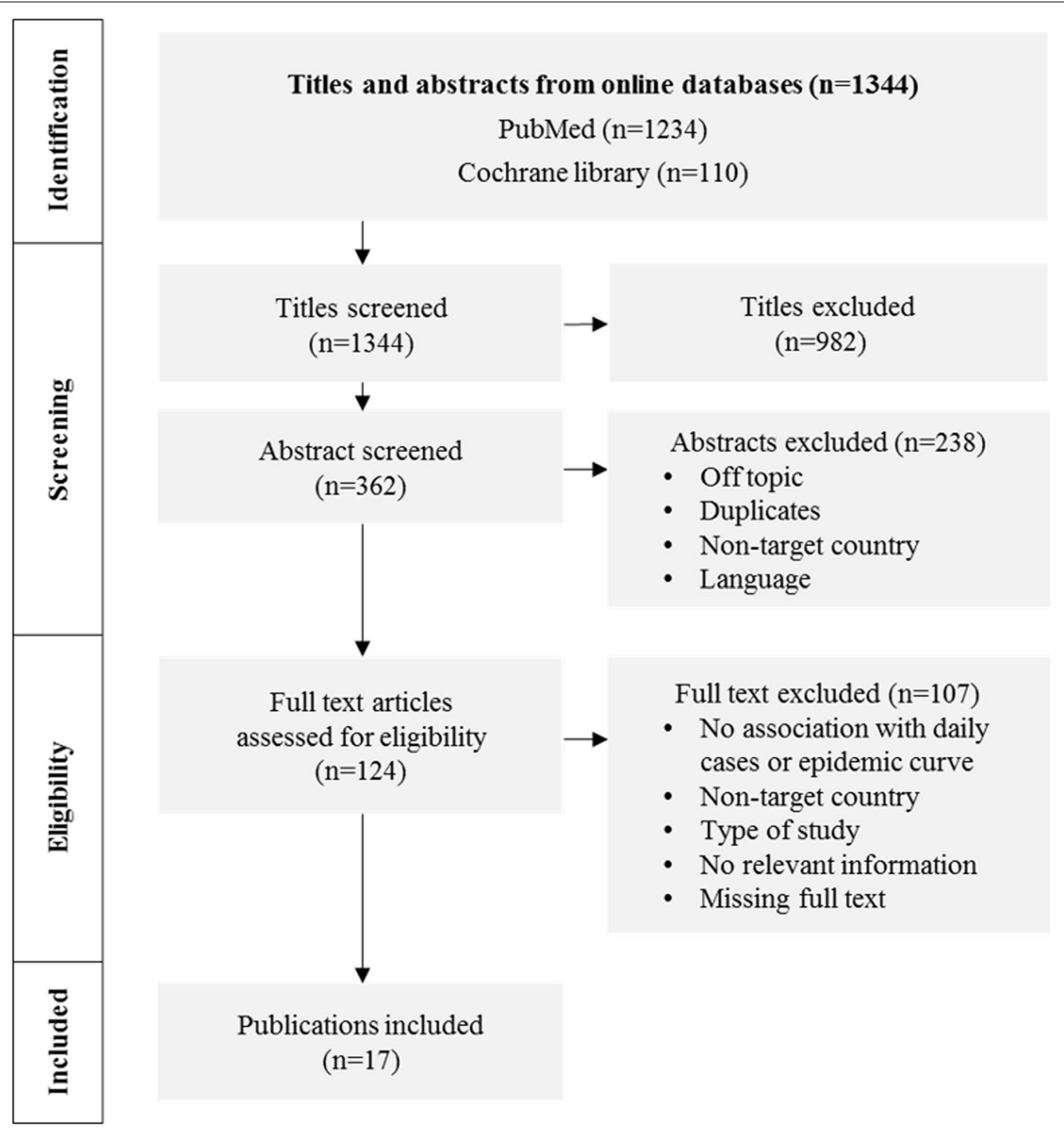

Fig. 1 PRISMA 2009 Flow Diagram. Search results and selection process of the studies on containment measures influencing the COVID-19 epidemic curve in the nine targeted countries. Targeted countries were Sweden, Italy, Germany, South Korea, Nepal, Mexico, Nigeria, Colombia, and India

three-persons household with each level of complete, nearly-complete, medium, and no quarantine to have 7 , 8,12 and 20 secondary infections, respectively, during 14 days [23]. In large households with 6 persons, 16, 19, 29 , and 43 secondary infections in 14 days respectively were predicted for each of the quarantine completion level, suggesting that a higher adherence to quarantine and a smaller household contribute to a lower number of secondary cases. In South Korea, during the outbreak, there was a positive correlation of compliance with lockdown measures and a decline in the confirmed cases [24]. Likewise, "home office" and the delay of school opening led to a marked transmission reduction.
Choi and Ki simulated the epidemic in South Korea and predicted nearly 5 million COVID-19 cases without any measures, while the lockdown could reduce the transmission rate by $90 \%$ to $99 \%$ [25-27]. The combination of different mitigation measures seems to be crucial for reducing infections and deaths [26], just as the increased compliance with the measures [28]. In Veneto, Italy, seventeen days after the lockdown strategy, 658 hospitalized cases (95\% CI 618-698) could be prevented and the peak of the curve was delayed by 3 days [29]. In Italy, measures such as "red zone" (lockdown in ten towns in Lombardy) effectively contained 
the spread of the infection and the general lockdown had a positive effect in other regions of Italy [30].

A modelling study in India found that within 21,42 , and 60 days lockdown periods, the number of cases (378,036 infections without intervention) was reduced to 70,424 after 110 days in the 21 days lockdown-scenario, and was additionally reduced to 42,950 in the 42 days scenario, but no additional reduction by prolonged lockdown of more than 42 days [31]. Another modelling study in France showed that the isolation of individuals with no or mild symptoms was not sufficient to reduce the number of confirmed cases, however, both in France and North-Italy, a substantial case reduction could be achieved by a large-scale reduction of social interactions [32]. A study in South Korea estimated the effective reproduction number $\left(R_{0}\right)$ to be 1.5 (95\% CI 1.4-1.6), the intrinsic growth rate to be 0.6 (95\% CI 0.6-0.7) and the "deceleration of growth" to be 0.8 (95\% CI 0.7-0.8), which indicate for sub-exponential growth dynamics of COVID-19 [33].

\section{Reduction of peak prevalence, cumulative incidence, and $R_{0}$ by containment measures}

A study in Italy and Spain comparing daily percent increase of diagnosed cases, deaths, and ICU admission before and after the national lockdowns showed that before lockdown, daily percent of incidence was high in Spain $(38.5 \%$ of diagnosed cases, $59.3 \%$ of deaths, $26.5 \%$ of ICU admissions) and less in Italy (21.6\%, $32.8 \%$, and $16.7 \%$ respectively), however, after the first lockdown, incidence was considerably lower in both countries $(11.9 \%, 17.6 \%$, and $9.6 \%$ in Spain, respectively, and $2.5 \%, 13.7 \%$, and $3.7 \%$ in Italy) [34]. After the second and more restrictive lockdown, particularly in Italy, all outcomes declined $(-2.0 \%,-0.2 \%$, and $-16.8 \%$ respectively), and so it happened in Spain $(-2.7 \%,-1.8 \%$, and $-5.6 \%$ respectively).

A modelling study in India showed that if $50 \%$ of symptomatic cases are in quarantine within three days after developing symptoms, assuming a minimal basic reproduction number $R_{0}$ of 1.5 before symptoms develop, the decrease of the cumulative incidence was $62 \%$ and of the peak prevalence was $89 \%$. In contrast, when assuming that $R_{0}$ was 4 and the infectiousness of asymptomatic cases was half compared to symptomatic cases, the estimated cumulative incidence will decrease by only $2 \%$ and the peak prevalence by $8 \%$ [35]. In another modelling study in India, lockdown measures reduced the basic reproduction number from 2.3 before the lockdown to 0.15 after the measure [36].

\section{Age specific infection rates and case fatalities}

A study in Germany showed that after establishing physical distancing in week 12, people aged 15-34 years played a predominant role in the spread of the disease compared to older (35-39 years) and younger age groups (10-14 years), assuming that the non-adherence to social distancing was frequent in this age group [37].

In Korea, Daegu province, the outbreak generally began in the younger age groups, but case fatalities were the highest among people aged $\geq 80$ years $(12.1 \%)$, followed by those aged 70-79 years (5.6\%) [38]. In 66 laboratory confirmed fatal cases of COVID-19, the median age was 77 years (range, 35-93 years), and female-to-male ratio was 44:56. In South Korea, the crude case-fatality was higher among males $(1.1 \%)$ compared to females $(0.4 \%)$ and increased with older age [33].

\section{Risk of importation and airport measures}

One of the first measures implemented by the Italian government was to suspend flights from China and install in air-ports' checkpoints with thermoscans. However, this measure appeared not to be very effective to contain the epidemic [30]. Mandal et al. found in a modelling study in India that airport screening of symptomatic arrivals will lead to a delay of 2.9 days in the predicted "average time to epidemic (days to reach a prevalence of 1000 cases)" [35]. In order to get a delay of 20 days, an additional $90 \%$ coverage in the screening of asymptomatic passengers will be needed, which is difficult to achieve, however, there are additional benefits of identifying asymptomatic arrivals rather than screening only symptomatic cases [35].

\section{The shape of the epidemic COVID-19 curves and determinants in 9 countries Cumulative and daily infections and deaths}

Figure 2 shows the cumulative incidence of COVID-19 until the end of May 2020 (both laboratory confirmed and non-confirmed). There are mainly two types of epidemic curves; in Germany, Italy, and South Korea, a quick increase in cases can be seen followed by a slow-down of the transmission, while there was almost a linear increase in Sweden. In the LMICs, we see an exponential increase of cases (Fig. 2; Table 3). Containment measures were implemented as a response, which in some countries happened before the first case was confirmed (minus values in Table 3), while some were shortly after the first case, and others occurred later in time. In five countries, which had already reached the peak of the wave before May 31, the length of the critical period (from the start of the wave to its peak) was between 44 days (South Korea and Italy) 


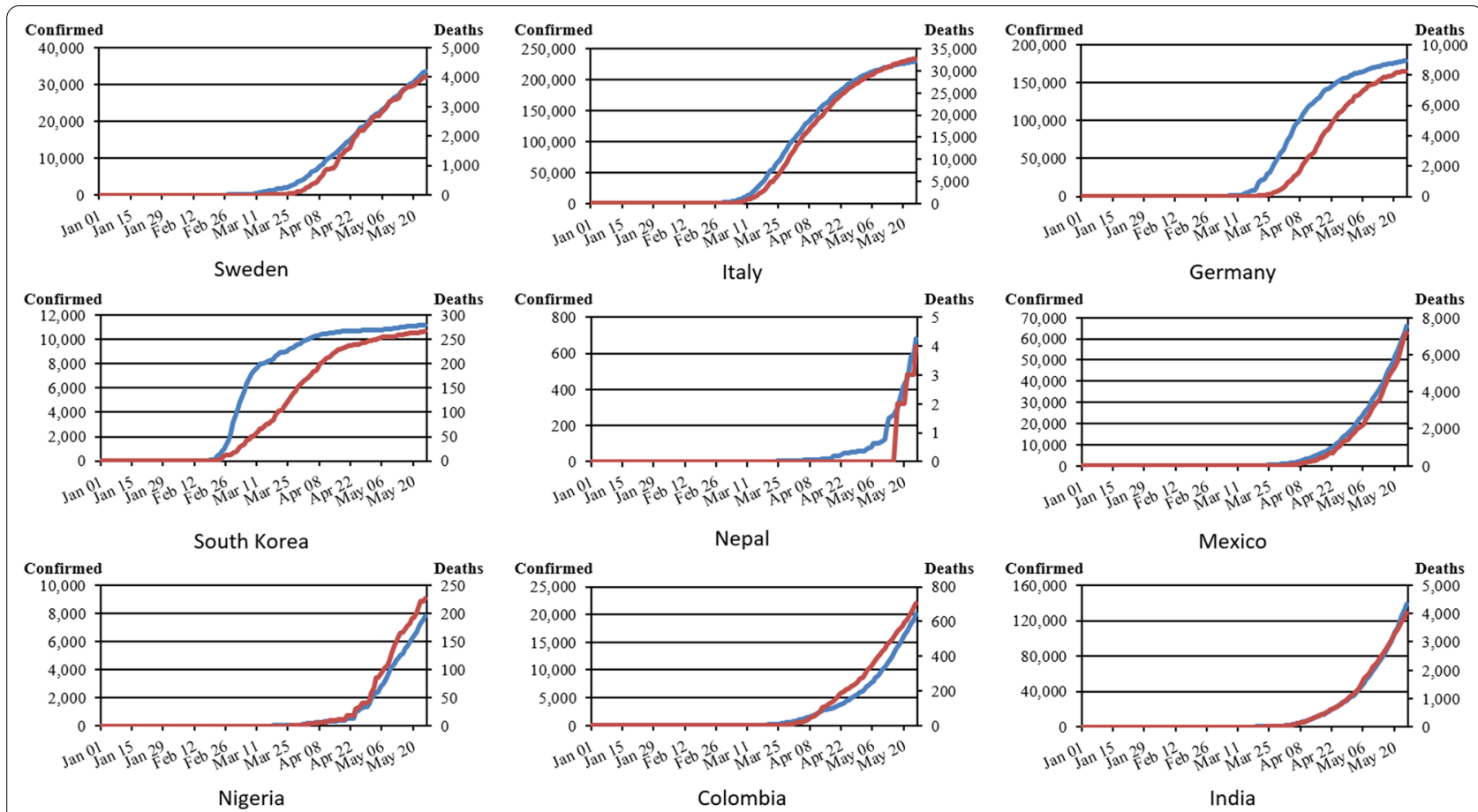

Fig. 2 Cumulative incidence of COVID-19 cases ("cases of infection" or "cases") and deaths. Blue=Cumulative cases of infection, Red=Cumulative deaths

Table 3 Critical period of infection and delay to the containment measures in nine target countries

\begin{tabular}{|c|c|c|c|c|c|c|c|}
\hline Country & $\begin{array}{l}\text { Delay to the } \\
\text { first action }\end{array}$ & $\begin{array}{l}\text { Delay to the full } \\
\text { action }^{\text {b }}\end{array}$ & $\begin{array}{l}\text { First case } \\
\text { confirmed }\end{array}$ & Peak date $^{c}$ & Critical period $^{d}$ & No. of cases at peak & No. of deaths at peak \\
\hline Germany & -2 days $^{\mathrm{e}}$ & $\begin{array}{l}56 \text { days (except public } \\
\text { transport) }\end{array}$ & 27 Jan & $27 \mathrm{Mar}$ & 61 days & 50,871 & 342 \\
\hline Italy & -7 days $^{\mathrm{e}}$ & 41 days & $31 \mathrm{Jan}$ & $21 \mathrm{Mar}$ & 51 days & 53,578 & 4825 \\
\hline Sweden & 39 days & $\begin{array}{l}65 \text { days (except public } \\
\text { events, public transport, } \\
\text { and internal traveling) }\end{array}$ & $31 \mathrm{Jan}$ & $24 \mathrm{Apr}$ & 85 days & 17,567 & 2152 \\
\hline South Korea & 12 days & $\begin{array}{l}36 \text { days (except public } \\
\text { transport) }\end{array}$ & $20 \mathrm{Jan}$ & $03 \mathrm{Mar}$ & 44 days & 5186 & 28 \\
\hline Mexico & 1 days & 32 days & 28 Feb & 27 May & 90 days & 78,023 & 8597 \\
\hline Colombia & -44 days $^{\mathrm{e}}$ & 20 days & $06 \mathrm{Mar}$ & Not yet reached & Ongoing & Not yet reached & Not yet reached \\
\hline India & -4 days $^{e}$ & 51 days & $30 \mathrm{Jan}$ & Not yet reached & Ongoing & Not yet reached & Not yet reached \\
\hline Nigeria & -36 days $^{\mathrm{e}}$ & 31 days & 28 Feb & Not yet reached & Ongoing & Not yet reached & Not yet reached \\
\hline Nepal & 50 days $^{e}$ & 60 days & $25 \mathrm{Jan}$ & Not yet reached & Ongoing & Not yet reached & Not yet reached \\
\hline
\end{tabular}

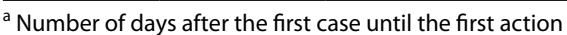

${ }^{\mathrm{b}}$ Number of days after the first case until the full action; full action means complete implementation to close schools, close workplaces, cancel public events, ban public gatherings, close public transportations, ban internal traveling, ban international traveling, and promote public campaigns

'Date with the peak number of newly confirmed cases; if the event with the highest number of daily cases was on May 30 or thereafter, it was considered "not yet reached" the peak

d Number of days after the first case until the peak date with the highest number of cases; if the peak was "not yet reached," the critical period was considered "ongoing"

${ }^{\mathrm{e}}$ Minus values in the delay to the first action mean the countries started with initial containment measures before the first case was confirmed 
and 90 days (Sweden), with Germany (61 days) in the middle. All LMICs did not reach the peak until 31 May 2020 , because they had particularly long critical periods from 90 to 130 days (Colombia, Mexico, Nigeria, India, and Nepal).

Figure 3 illustrates that only Germany, Italy, and South Korea show the typical epidemic curve with a sharp increase to the peak and then a slower decrease of cases skewed to the right. The curves of India, Mexico, and Nepal have a similar shape, but only during of the initial part, as they did not reach the peak at the time. Sweden, with a "hands-off" policy and relaxed strategy, has a flat and prolonged curve of new cases; likewise, Nigeria has a flat and prolonged curve, which was limited to the low testing capacity.

As these findings seem to contradict the model predicted by Ferguson et al. to be high and stiff when there is no distancing measure while low and prolonged if containment measures were employed [3], we had a closer look at the stringency of containment measures and peoples' compliance with these measures $[16,18]$.

\section{The stringency of the containment measures and people's compliance level}

Figure 4 and Table 4 shows the SI over time. Some countries started late but were then very fast with containment measures (Nepal, Mexico, and Italy) while others started early but then strengthened the measures stepby-step (Germany, South Korea, and India). Others opted for less stringent measures, particularly Sweden and South Korea (after a month of strict measures). The LMICs were generally more stringent than the HICs.

Human movement after the introduction of containment measures in six countries are given in Fig. 5, which shows that in Colombia (similar to Italy, India, Nigeria, and Nepal), people stayed at home and did not follow many extra-domestic activities. Germany (similar to Mexico) illustrates a less strict restriction of mobility: people stayed more at home with limited recreational activities strictly, but used the public transport and visited public parks more frequently. In Sweden and South Korea, the less stringent containment policy led people to continue going to work, using pharmacies/groceries, and using public transports almost as usual, and increasing visits to parks rather than other recreational activities.

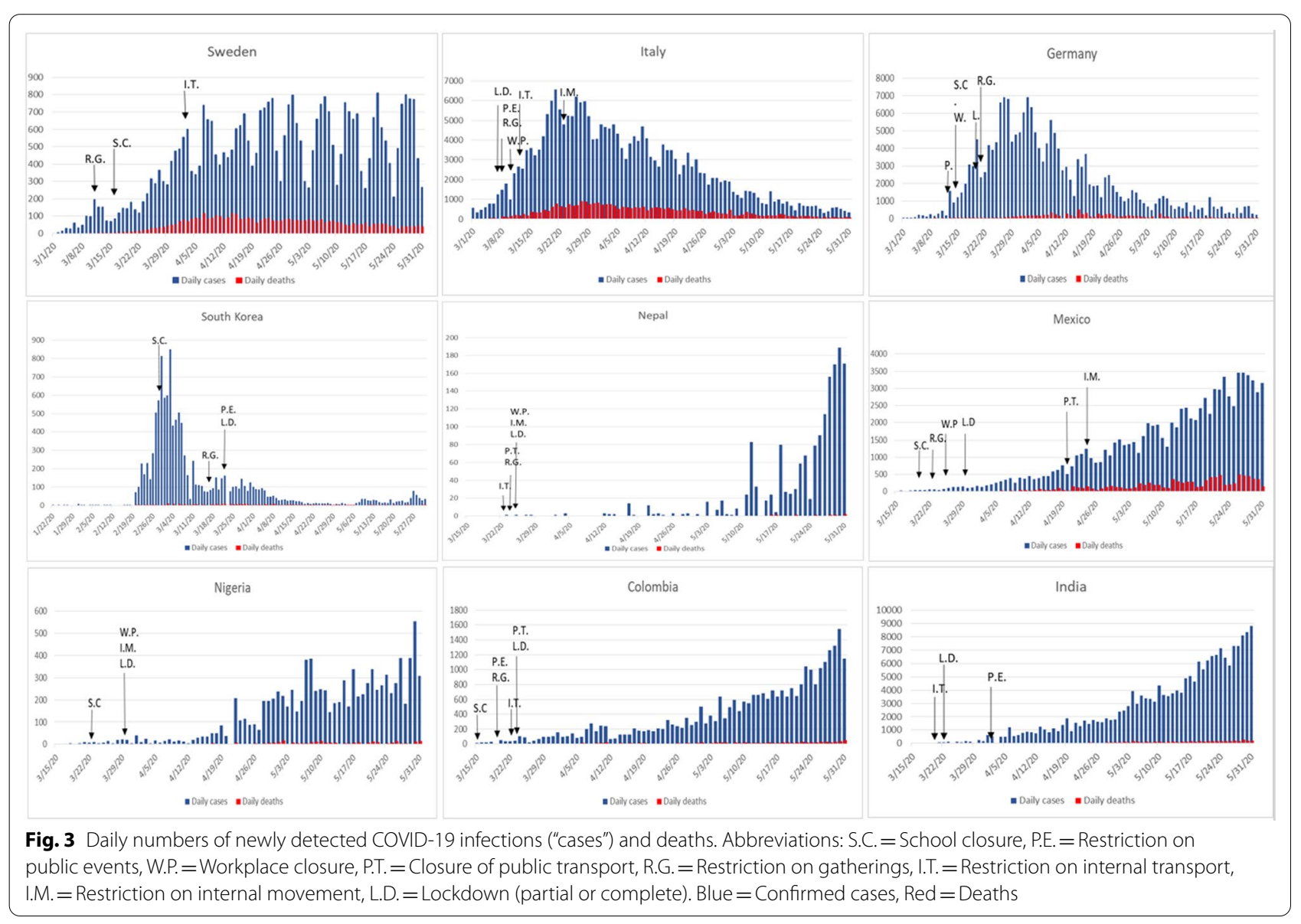




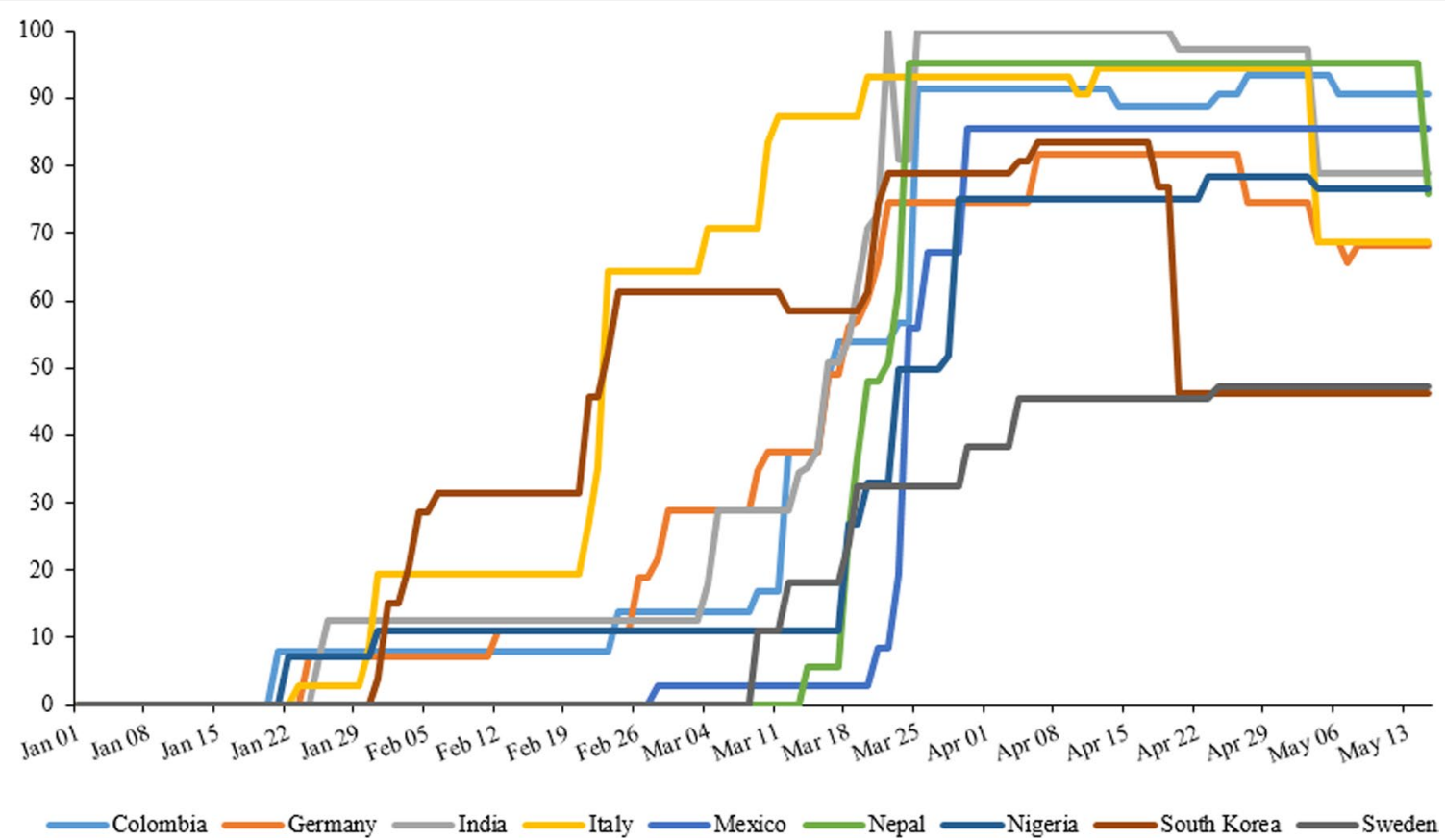

Fig. 4 The stringency index reflecting the strength of containment measures in nine selected countries. Methodology for the index estimation followed that of Hale et al., using the information of governmental actions provided by the Oxford COVID-19 Government Response Tracker [7,8]

Table 4 Descriptive statistics of stringency index per country and sub-country, for the period of Jan-May 2020

\begin{tabular}{|c|c|c|c|c|c|c|c|c|}
\hline & \multirow[t]{2}{*}{ Mean } & \multirow[t]{2}{*}{ SD } & \multirow[t]{2}{*}{ Min } & \multicolumn{4}{|c|}{ Percentiles } & \multirow[t]{2}{*}{ Max } \\
\hline & & & & $25 \%$ & $50 \%$ & $75 \%$ & $95 \%$ & \\
\hline \multicolumn{9}{|l|}{ Countries } \\
\hline India & 58.09 & 38.87 & 0 & 10.19 & 79.17 & 96.3 & 100 & 100 \\
\hline Nepal & 56.86 & 39.19 & 0 & 16.67 & 81.02 & 96.3 & 96.3 & 96.3 \\
\hline Nigeria & 46.08 & 30.83 & 11.11 & 22.22 & 22.22 & 80.56 & 85.65 & 85.65 \\
\hline Colombia & 53.29 & 36.84 & 0 & 8.33 & 84.26 & 87.04 & 90.74 & 90.74 \\
\hline Mexico & 60.11 & 34.52 & 0 & 8.33 & 82.41 & 82.41 & 82.41 & 82.41 \\
\hline South Korea & 51.84 & 17.94 & 0 & 43.52 & 45.37 & 56.94 & 82.41 & 82.41 \\
\hline Italy & 64.71 & 29.85 & 0 & 60.19 & 69.91 & 91.67 & 93.52 & 93.52 \\
\hline Germany & 45.28 & 27.35 & 0 & 11.11 & 52.78 & 73.15 & 73.15 & 73.15 \\
\hline Sweden & 38.98 & 10.54 & 0 & 32.41 & 43.52 & 46.3 & 46.3 & 46.3 \\
\hline \multicolumn{9}{|l|}{ Sub-countries } \\
\hline India, Kerala & 68.09 & 35.22 & 10.19 & 26.85 & 81.94 & 100 & 100 & 100 \\
\hline Nepal, Kathmandu & 69.85 & 34.88 & 16.67 & 22.22 & 92.59 & 96.3 & 96.3 & 96.3 \\
\hline Nigeria, Abuja & 59.51 & 27.85 & 22.22 & 22.22 & 80.56 & 82.87 & 85.65 & 85.65 \\
\hline Colombia, North Santander & 63.79 & 33.01 & 8.33 & 34.26 & 87.04 & 87.96 & 90.74 & 90.74 \\
\hline Mexico, Nuevo León & 60.11 & 34.52 & 0 & 8.33 & 82.41 & 82.41 & 82.41 & 82.41 \\
\hline South Korea, Daegu & 55.47 & 15.75 & 31.48 & 43.52 & 52.78 & 75.93 & 82.41 & 82.41 \\
\hline Italy, Lombardy & 75.63 & 19.76 & 19.44 & 62.96 & 85.19 & 91.67 & 93.52 & 93.52 \\
\hline Germany, Baden-Württemberg & 53.52 & 22.68 & 11.11 & 32.87 & 64.35 & 73.15 & 73.15 & 73.15 \\
\hline Sweden, Västra Götaland & 38.98 & 10.54 & 0 & 32.41 & 43.52 & 46.3 & 46.3 & 46.3 \\
\hline
\end{tabular}



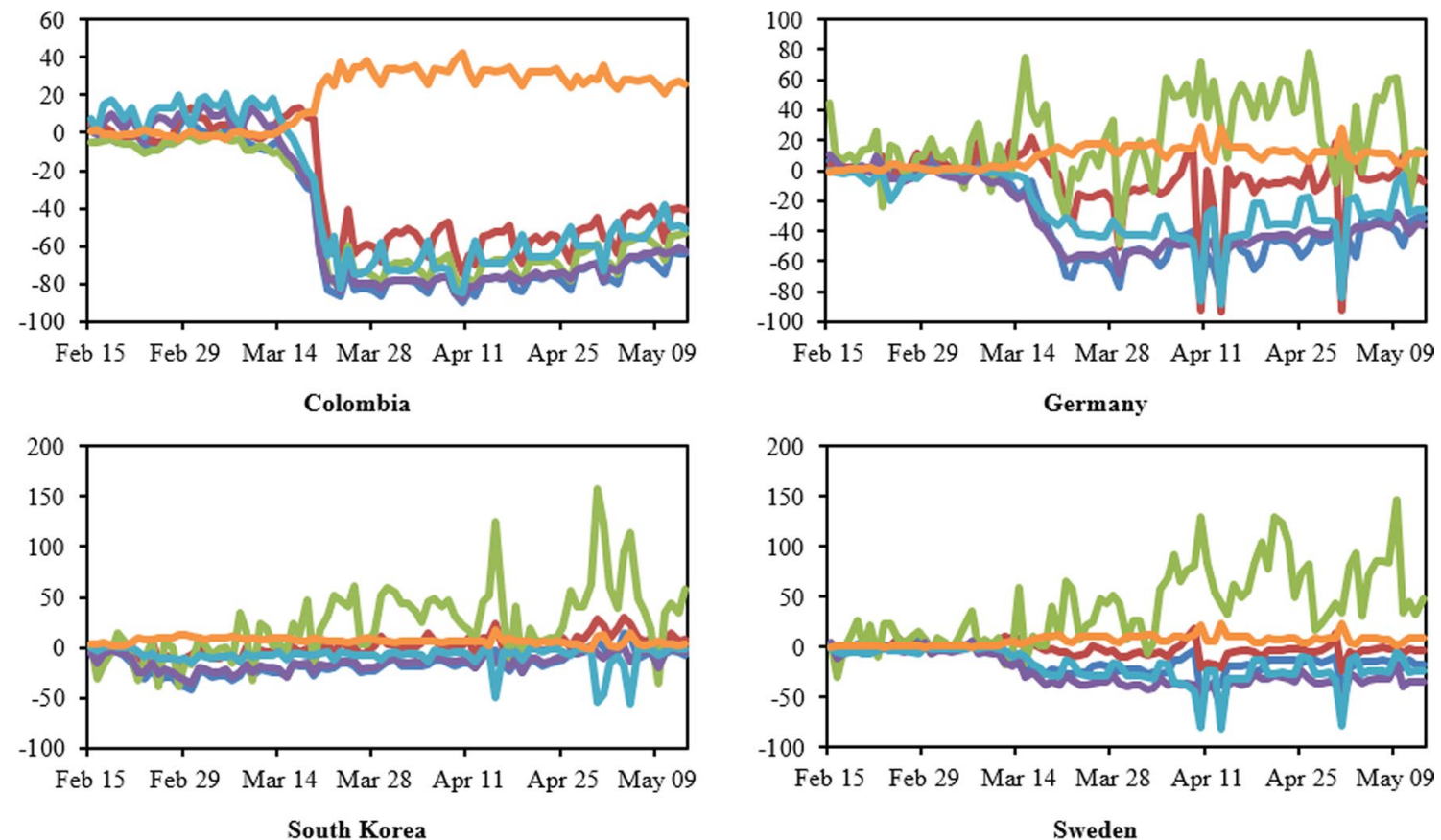

Feb 15 Feb 29 Mar 14 Mar 28 Apr 11 Apr 25 May 09

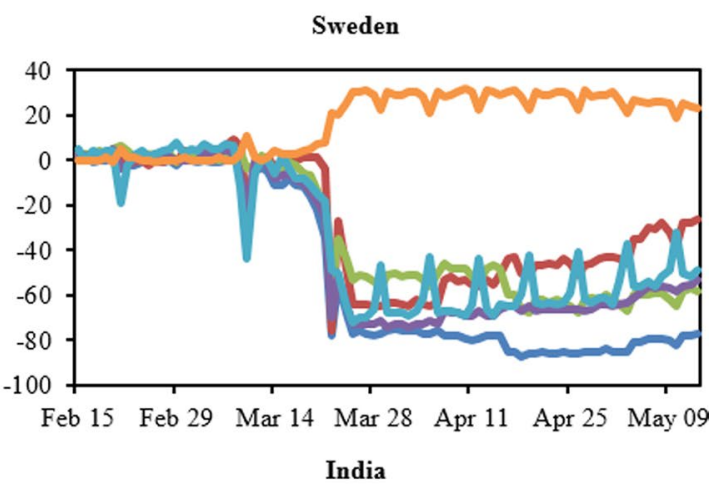

Fig. 5 Human mobility after the start of containment measures in six countries (Colombia, Germany, South Korea, Sweden, Nepal, and India). Blue $=$ Retail and recreation, Red = Grocery and pharmacy, Green $=$ Parks, Purple $=$ Transit stations, Light blue $=$ Workplaces, Orange $=$ Residential

\section{Containment measures shaping the epidemic curve (Interrupted time-series analysis)}

Findings from the time-series analysis for the infection and death rates showed different patterns across the nine countries (Tables 5 and 6; Fig. 6).

- India: At baseline (prior to any intervention), infection rates showed a slight increase, which reversed temporarily at the time of the first intervention $(-0.148 ; \mathrm{p}<0.05)$ before starting to increase again at the following intervention $(0.14 ; \mathrm{p}<0.05)$. At sub-country level in Kerala, a fairly similar scenario was observed with exception for the rate at and after the first intervention. The death rate followed the scenario of the infection but at a slower pace.
- Nepal: The baseline trend did not indicate a statistically significant rate of change, but showed an increasing trend after the first intervention (0.004; $\mathrm{p}<0.05)$. Although a slightly different rate of change was observed at sub-country level (Kathmandu), generally, the rate of reduction followed a similar trend of increasing infection rates throughout the period. Mortality rates were low and therefore no pattern of change was observed.

- Nigeria: The baseline trend did not indicate a rate of change but showed an increasing trend throughout the follow-up period. In Abuja, the same trend was observed but at a higher rate; however, a decreasing trend in infection rate was observed after the second intervention. The death rates at country and sub- 
Table 5 Interrupted time-series regression of infection rate per 100,000 in relation to countries- and sub-countries stringency Indices (Intervention)

\begin{tabular}{|c|c|c|c|c|c|c|c|c|c|}
\hline \multirow[b]{2}{*}{ Country level } & \multicolumn{9}{|c|}{ Cases per 100,000} \\
\hline & India & Nepal & Nigeria & Colombia & Mexico & South Korea & Italy & Germany & Sweden \\
\hline Baseline trend & $0.0001^{*}$ & -0.001 & $7.9 \times 10^{-6}$ & $0.001^{*}$ & $0.006^{*}$ & 0.004 & 0.002 & $0.136^{*}$ & $0.025^{*}$ \\
\hline At intervention 1 & $-0.148^{*}$ & -0.01 & 0.003 & $0.561^{*}$ & $-2.676^{*}$ & $8.160^{*}$ & $-12.819^{*}$ & $61.896^{*}$ & $-0.073^{\mathrm{a}}$ \\
\hline $\begin{array}{l}\text { Trend after inter- } \\
\text { vention } 1\end{array}$ & $0.042^{*}$ & $0.004^{*}$ & $0.006^{*}$ & $0.114^{*}$ & $0.461^{*}$ & $-0.181^{*}$ & $3.135^{*}$ & $-1.368^{*}$ & $1.787^{*}$ \\
\hline At intervention 2 & - & - & - & - & - & 0.626 & $31.33^{*}$ & - & -3.262 \\
\hline $\begin{array}{l}\text { Trend after inter- } \\
\text { vention } 2\end{array}$ & - & - & - & - & - & $0.124^{*}$ & $-4.857^{*}$ & - & -0.718 \\
\hline At intervention 3 & 0.384 & -0.509 & $0.604^{*}$ & 0.946 & - & -0.119 & -4.98 & -1.213 & -6.781 \\
\hline $\begin{array}{l}\text { Trend after inter- } \\
\text { vention } 3\end{array}$ & $0.098^{*}$ & $0.142^{*}$ & $0.02^{*}$ & $0.316^{*}$ & - & $-0.069^{*}$ & 0.557 & $0.973^{*}$ & -1.303 \\
\hline $\begin{array}{l}\text { General trend } \\
\text { after all levels } \\
\text { of intervention }\end{array}$ & $0.14^{*}$ & $0.146^{*}$ & $0.025^{*}$ & $0.432^{*}$ & $0.467^{*}$ & $0.016^{*}$ & $-1.163^{*}$ & $-0.232^{*}$ & -0.21 \\
\hline $\begin{array}{l}\text { Sub-country } \\
\text { level }\end{array}$ & Kerala & Kathmandu & Abuja & North Santander & Nuevo León & Daegu & Lombardy & $\begin{array}{l}\text { Baden-Württem- } \\
\text { berg }\end{array}$ & Västra Götaland \\
\hline Baseline trend & $0.005^{*}$ & 0.006 & $0.014^{*}$ & $0.022^{*}$ & $0.021^{*}$ & $6.33^{*}$ & $3.33^{*}$ & $0.838^{*}$ & $0.401^{*}$ \\
\hline At intervention 1 & $0.33^{*}$ & -0.117 & 0.091 & 0.432 & $-1.214^{*}$ & $105.136^{*}$ & $130.759^{*}$ & $75.703^{*}$ & $12.026^{\mathrm{a}}$ \\
\hline $\begin{array}{l}\text { Trend after inter- } \\
\text { vention } 1\end{array}$ & $-0.011^{*}$ & -0.006 & 0.076 & -0.021 & $0.164^{*}$ & $-10.589^{*}$ & $-5.785^{*}$ & $-2.468^{*}$ & 0.433 \\
\hline At intervention 2 & - & - & - & - & - & - & - & - & - \\
\hline $\begin{array}{l}\text { Trend after inter- } \\
\text { vention } 2\end{array}$ & - & - & - & - & - & - & - & - & - \\
\hline At intervention 3 & $0.395^{*}$ & 0.127 & 0.91 & 0.439 & - & 30.13 & -3.432 & 7.368 & 14.163 \\
\hline $\begin{array}{l}\text { Trend after inter- } \\
\text { vention } 3\end{array}$ & $0.170^{*}$ & 0.026 & -0.069 & -0.02 & - & $4.223^{*}$ & 0.934 & $1.646^{*}$ & -0.639 \\
\hline $\begin{array}{l}\text { General trend } \\
\text { after all levels } \\
\text { of intervention }\end{array}$ & $0.165^{*}$ & 0.026 & 0.021 & -0.019 & $0.185^{*}$ & $-0.036^{*}$ & $-1.52^{*}$ & 0.016 & 0.195 \\
\hline
\end{tabular}

Intervention 1 measured at 50th, intervention 2 measured at 75th and intervention 3 measured at 95th percentile

* Significant change $(p<0.05)$

${ }^{\mathrm{a}}$ intervention 1 is measured at 10th percentile instead of 50th (only in Sweden)

country levels followed the same trend but with an increasing death rate at baseline and after intervention one but decreased following to the second intervention. Nevertheless, none of these changes showed a significant trend.

- Colombia: The increasing infection rates at baseline were minimal but significant and continued to increase significantly in spite of the second and third intervention. In North Santander, the rate of infection started with an increasing trend but responded to both interventions with a mild decline. The same scenario was observed for the death rates at country and sub-country levels.

- Mexico: Mexico had minimal changes in the stringency index after the first intervention but was successful in reducing the infection and death rates significantly thereafter (infection: $-2.676 ; \mathrm{p}<0.05$, death: $-0.359 ; \mathrm{p}<0.05)$. However, after this initial success both infection and death rates increased shortly after the intervention; this trend was similar in Nuevo Leon.

- South Korea: South Korea had a continuous increase in the SI with three different intervention episodes. At baseline, the country showed an increasing infection rate until the first intervention before cases started to decline significantly $(-0.181 ; \mathrm{p}<0.05)$, which was continued after the third intervention $(-0.119 ; \mathrm{p}<0.05)$. Daegu Province (where more than half of the cases occurred) followed a similar trend, but the increasing stringency measures succeeded in reducing the overall infections $(-0.036 ; \mathrm{p}<0.05)$. The impact of the interventions on death rates was even more significant both at country and sub-country level.

- Italy: The rate of infection was much higher in Lombardy compared to the whole country. Nevertheless, 
Table 6 Interrupted time-series regression of death rate per 100,000 in relation to countries- and sub-countries stringency Indices (Intervention)

\begin{tabular}{|c|c|c|c|c|c|c|c|c|c|}
\hline \multirow[b]{2}{*}{ Country level } & \multicolumn{9}{|c|}{ Deaths per 100,000} \\
\hline & India & Nepal & Nigeria & Colombia & Mexico & South Korea & Italy & Germany & Sweden \\
\hline Baseline trend & $2.3 \times 10^{-6}$ & 0.000 & $0.001^{*}$ & $0.002^{*}$ & $0.000^{*}$ & 0.001 & 0.001 & $0.0003^{*}$ & 0.0002 \\
\hline At intervention 1 & $-0.004^{*}$ & - & - & - & $-0.359^{*}$ & $0.039^{*}$ & $-1.562^{*}$ & $1.056^{*}$ & $-1.033^{*}$ \\
\hline $\begin{array}{l}\text { Trend after inter- } \\
\text { vention } 1\end{array}$ & $0.001^{*}$ & - & - & - & $0.055^{*}$ & $0.002^{*}$ & $0.301^{*}$ & $0.034^{*}$ & $0.303^{*}$ \\
\hline At intervention 2 & - & - & $0.022^{*}$ & - & - & -0.015 & $6.704^{*}$ & - & 0.054 \\
\hline $\begin{array}{l}\text { Trend after inter- } \\
\text { vention } 2\end{array}$ & - & - & 0.001 & - & - & $-0.007^{*}$ & $-0.413^{*}$ & - & 0.073 \\
\hline At intervention 3 & $0.027^{*}$ & 0.002 & -0.012 & $0.101^{*}$ & - & -0.006 & $-0.144^{*}$ & $-1.348^{*}$ & -4.665 \\
\hline $\begin{array}{l}\text { Trend after inter- } \\
\text { vention } 3\end{array}$ & -0.000 & 0.001 & -0.001 & $0.008^{*}$ & - & $0.005^{*}$ & -0.062 & $-0.778^{*}$ & $-0.451^{*}$ \\
\hline $\begin{array}{l}\text { General trend } \\
\text { after all levels } \\
\text { of intervention }\end{array}$ & 0.001 & 0.002 & 0.0002 & $0.01^{*}$ & $0.055^{*}$ & $-0.0004^{*}$ & $-0.174^{*}$ & $-0.043^{*}$ & -0.074 \\
\hline $\begin{array}{l}\text { Sub-country } \\
\text { level }\end{array}$ & Kerala & Kathmandu ${ }^{a}$ & Abuja & North Santander & Nuevo León & Daegu & Lombardy & $\begin{array}{l}\text { Baden-Württem- } \\
\text { berg }\end{array}$ & Västra Götaland \\
\hline Baseline trend & $7.78 \times 10^{-6}$ & - & 0.001 & $0.003^{*}$ & $0.002^{*}$ & 0.027 & $0.335^{*}$ & $0.003^{*}$ & $0.018^{*}$ \\
\hline At intervention 1 & - & - & 0.006 & - & -0.013 & $0.696^{*}$ & $28.27^{*}$ & $2.596^{*}$ & 0.146 \\
\hline $\begin{array}{l}\text { Trend after inter- } \\
\text { vention } 1\end{array}$ & - & - & -0.001 & - & $0.015^{*}$ & -0.009 & $-0.679^{*}$ & -0.01 & 0.271 \\
\hline At intervention 2 & - & - & - & - & - & - & - & - & -0.949 \\
\hline $\begin{array}{l}\text { Trend after inter- } \\
\text { vention } 2\end{array}$ & - & - & - & - & - & - & - & - & -0.248 \\
\hline At intervention 3 & -0.001 & - & -0.037 & -0.035 & - & $-0.745^{*}$ & -4.803 & $-1.633^{*}$ & - \\
\hline $\begin{array}{l}\text { Trend after inter- } \\
\text { vention } 3\end{array}$ & 0.002 & - & 0.009 & -0.005 & - & $-0.036^{*}$ & 0.019 & 0.026 & - \\
\hline $\begin{array}{l}\text { General trend } \\
\text { after all levels } \\
\text { of intervention }\end{array}$ & 0.002 & - & 0.008 & -0.002 & $0.017^{*}$ & $-0.018^{*}$ & $-0.325^{*}$ & 0.02 & 0.041 \\
\hline
\end{tabular}

Intervention 1 measured at 50th, intervention 2 measured at 75th and intervention 3 measured at 95th percentile

* significant change $(p<0.001)$

a No reported cases

${ }^{\mathrm{b}}$ Intervention 1 is measured at 10th percentile instead of 50th percentile (only in Sweden)

containment measures managed to reduce infection rates significantly at both levels (country: -1.163 ; $\mathrm{p}<0.05$; Lombardy: $-1.520 ; \mathrm{p}<0.05)$. The same results were obtained for the mortality, which equally maintained a significant decline after the interventions (country: $-0.174 ; \mathrm{p}<0.05$; Lombardy: -0.325 ; $\mathrm{p}<0.05)$.

- Germany: Germany showed an increasing incidence before imposing containment measures, but this rate started to significantly decline after the first intervention; this decline continued after the second and third interventions so that the rates could be reduced by $-0.232(\mathrm{p}<0.05)$. Baden-Württemberg followed a fairly similar trend. The death rates at country- and sub-country level showed similar trends.

- Sweden: Sweden started late in imposing containment measures with a low SI. Albeit the minimal average of the SI, the country managed to reduce the rate of infection immediately after the first intervention and continued through the following two interventions, although the reduction was statistically insignificant $(-0.21$ : $p>0.05)$. The picture was different in Västra Götaland where the containment measures failed to generally reduce the rate of infection significantly. The death rate followed a similar trend for both country and sub-country level.

\section{Discussion}

Effective containment measures: scoping review Main messages from the scoping review about the effect of containment measures on infection rates were 


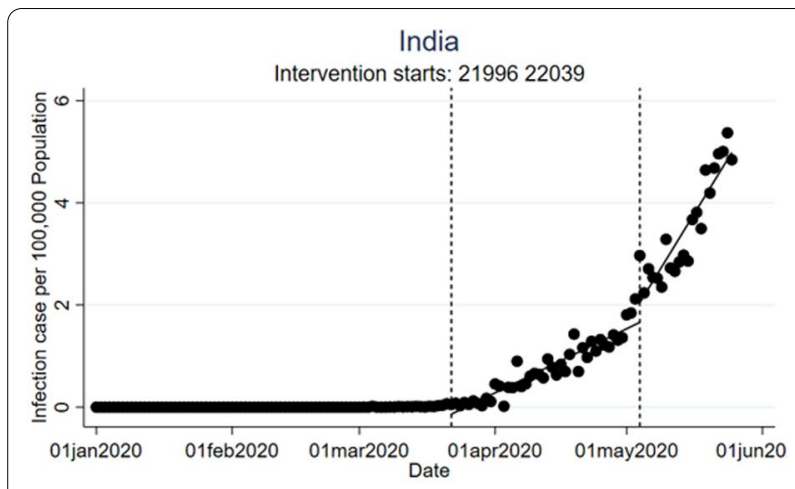

Intervention 1; Stringency index $=79.1$

Intervention 2; Stringency index $=100.0$

Italy

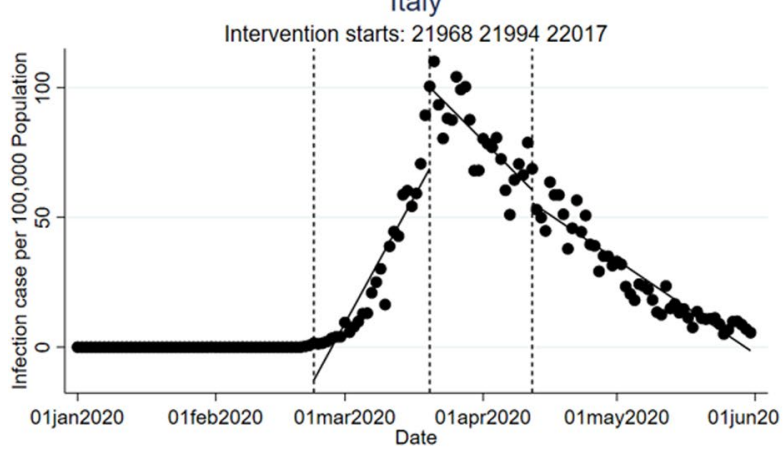

Intervention 1 ; stringency index $=69.9$

Intervention 2; stringency index $=91.7$

Intervention 3; stringency index $=93.5$

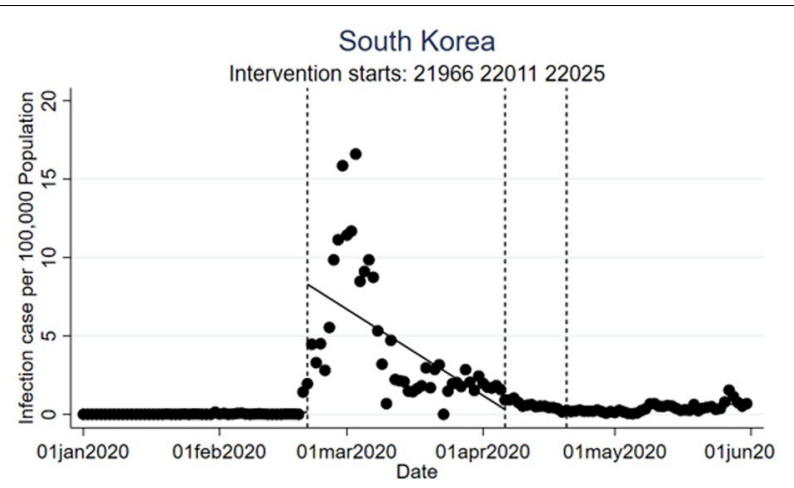

Intervention 1; Stringency index $=45.4$

Intervention 2; Stringency index $=56.9$

Intervention 3; Stringency index $=82.4$

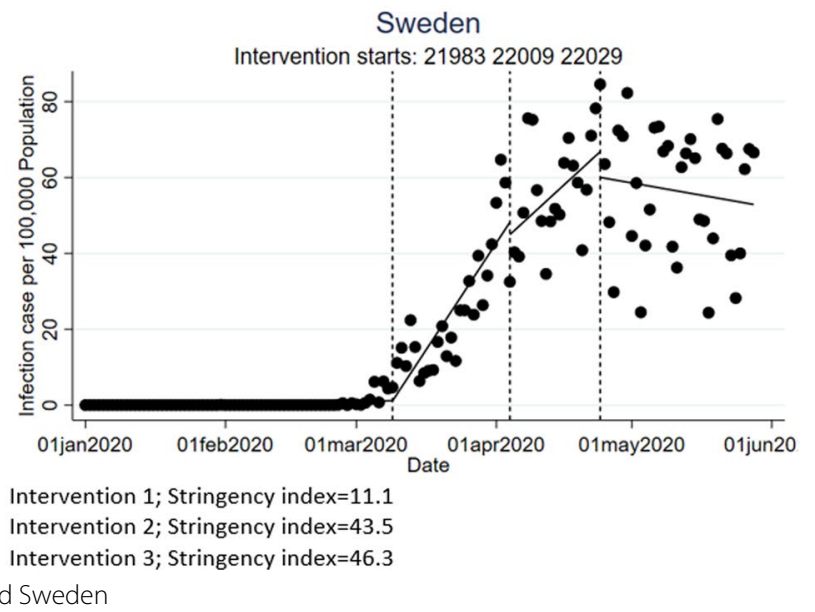

that containment measures, particularly when initiated early, could reduce the progression of the disease transmission (Italy) [21], reduce the basic reproduction number $R_{0}$ from 2.3 to 0.15 (India) [36], and delay the peak of the epidemic by 3 days in modelling studies [29, 35]. A combination of containment measures is more effective, leading to a reduction of secondary cases by 90 to $99 \%$ in South Korea [25]. In Spain and Italy, particularly the second intervention, when added to the first one, led to the reduction of infections [34]. However, the lockdown of mild and asymptomatic cases alone did not have much effect in modelling studies [32], and prolonged lockdown beyond 42 days did not have an additional benefit (India) [31]. Furthermore, fever checking in airports needs a very high coverage to be effective, particularly considering all asymptomatic arrivals [35]. Finding from our review came to the same conclusion-that containment measures ware effective in reducing the transmission dynamics, but only in HICs and only minimal in LMICs.

\section{Wealth and disease burden}

Our participant countries represented a range of income groups whereby Germany, Sweden, South Korea, and Italy belong to the high-income category in contrast to the LMIC group, which engulfs the rest of the countries. The country's wealth status has apparent implications, which is reflected in the distribution of the cumulative infection and death rates (Fig. 2). Higher income nations displayed a sharp increase of both infection and death rates at the early stages of the pandemic, which slowed down 4 to 6 weeks later, with the exception of Sweden which had a less-pronounced decline due to the "relaxed" containment policy. Among the LMICs, the increase of infections was stiffer and started earlier in time and continued throughout without reaching the peak during the observation period. This difference warrants further investigation. 


\section{Assessing the containment measures in LMICs and HICs}

The SI as a summary measure of the different components of the containment strategies implemented over time revealed the following (Fig. 4). High and long lasting SIs were found particularly in LMICs (India, Nepal, and Colombia) and lower SIs and/or shorter duration were observed in HICs, particularly in Sweden, South Korea, and Germany. Mobility data (Fig. 3) reflecting the compliance of people with the lockdown measures also seem to show that populations in LMICs were more compliant than those in HICs.

In South Korea, Germany, and Italy, the containment measures were successful in reducing infection rates and deaths, particularly when several restrictions were combined. In Sweden, the effect was also present but not statistically significant, which is explained by the minimal changes of lifestyle during the epidemic. Conversely, the effect in LMICs was disappointing in relation to strict containment measures imposed, particularly in India, Nepal, and Colombia. Despite the fact that peoples' compliance with the measures appears satisfactory, these countries have achieved minimal and only temporary reduction of infection rates or deaths. Also at the sub-country level, no apparent or sustained success could be observed. For instance, in Kerala, India, containment measures were particularly strict but only a minimal transient effect on transmission reduction could be observed.

\section{Likely causes for the unsuccessful containment measures in LMICs}

Data from LMICs are usually less reliable than those from HICs. Systematic testing is rarely being done, not even in symptomatic cases, and the number of infections and deaths is mainly health service based. However, the information on the sharp increase of new infections and deaths is worrying enough although the real burden is most likely to be much higher.

We assume that the high proportion of people working in the informal economic sector, particularly those in vulnerable employments (India, $74.5 \%$ vs. Germany, $5.7 \%$ ), explains why lockdown measures are impossible to comply with in poverty areas. "No work, no food" illustrates that the majority of people in these areas cannot afford to stay at home. This is not captured by our human mobility analysis which rests on the ownership of a smart phone and does not reflect the movements of the poor. In other words: the lockdown measures are not followed by a large population segment which drives the virus transmission.

\section{Comparison with similar studies from across the world} The additional literature search after completing the scoping review and the analysis of data at the earlier stages of the pandemic added the following information: A study including 41 countries showed that containment measures including non-pharmaceutical interventions were effective in reducing Covid-19 transmission, with some measures greater than others [39]. A recent study from India found that the timevarying reproduction number $(R(\mathrm{t}))$ was reduced in several states as a result of various containment measures [40]. It was shown that the reproduction number increases with higher population density as it facilitates the transmission of the virus. Thus, mobility restrictions could markedly bring down the COVID-19 spread in densely populated regions (see also Table 1 on population density) [41, 42]. However, such restrictions could not be implemented for a long period in LMICs, where the proportion of people belonging to the informal sector is high, as discussed above.

Other studies showed the impact of containment on mobility. A study by Barbieri et al. found in ten countries a decrease of private mobility during the first wave of the pandemic [43]: people abstained from walking (11.3\% reduction in Iran), cycling or driving a car (10.2\% and $13.7 \%$ reduction, respectively in Ghana). Also, the use of public transportation decreased the most significantly in Iran ( $18.7 \%$ less use of trams) and Australia (7.2\% less use of trains) and Norway (decreased use of buses, $-19.4 \%$, and airplanes, $-4.9 \%$ ).

Another recent study which summarized guidance for low-income countries said that authorities in African countries could learn from China to improve emergency responses to pandemics, be more proactive, and be committed to planning and performing long-term plans for coming pandemics. Furthermore, there should be a promotion of hygiene and public participation as a routine application in all communities in Africa. Liaising with medically sophisticated countries will facilitate real-time information, assuring that gaps between advanced countries and LMIC like Africa are reduced. African countries should also increase their capacities to make their anti-epidemic elements such as personal protective equipment and testing kits to flatten the curve [44].

These study results were in line with the results of the here presented study (reduced mobility during the lockdown, population density as a risk factor for COVID-19 spread), but did not distinguish between rich and poor countries. 


\section{Study limitations}

This study has utilized existing records of national and sub-national infection and death cases as reported by established sources [7-14], including the pragmatic measure of SI and Google mobility data as described elsewhere $[16,18]$. Just like the case of data reporting for other diseases, the authors acknowledge the possible incorrect disease classification of diagnosis particularly in LMICs including the frequent underreporting of mortality and morbidity data. However, information sources in the current study have been most useful in several recent epidemiological studies. In addition, the SI is deemed as a novel index to be applied in research, but our results suggest plausible interpretations of this index which appear to follow what was expected in the corresponding countries. Since the Google mobile data is prone to several limitations as acknowledged by their providers [18], we attempted to interpret this information more cautiously and only integrated their records in the descriptive statistics to aid the study discussion.

\section{Conclusion}

Compared to HICs, the transmission dynamics seem to follow different paths in LMICs requiring different and more context-specific strategies in order to contain the spread of the virus and protect the most disadvantaged societies. This is certainly a novel challenge for the global health community and experiences from local settings will likely help to shape national and global policies and find new ways of dealing with the COVID-19 pandemic and its disastrous impact on peoples 'lives.

\footnotetext{
Abbreviations

COVID-19: Corona virus disease, 2019; GDP: Gross domestic product; HIC: High-income countries; ICU: Intensive care unit; LMIC: Low-middle income countries; MIC: Middle-income countries; NPI: Non-pharmaceutical interventions; SI: Stringency index.
}

\section{Supplementary Information}

The online version contains supplementary material available at https://doi. org/10.1186/s12879-021-06714-3.

Additional file 1: Table S1. Description of the included studies in literature review.

\section{Acknowledgements}

This work is based on an enthusiastic team of mainly young researchers with a vision to contribute to a better life particularly for the poor in low-and middle-income countries. No specific funding has been obtained.

\section{Authors' contributions}

SYJ, LHA, DJC, SDM and AK conceptualized and designed the paper, which was drafted by SYJ. TRR, AAA, DJC, RCS, MAC, IHO, EAS, and PO conducted the screening of the full-articles of the included studies independently. SYJ, DJC and AK did a critical revision of the paper and jointly evaluated the themes and critically appraised each theme in relation to the research questions. LHA conducted the time-series analysis and BKK, MA and SYJ performed further descriptive statistics. The final draft of the paper was approved by all the authors. All authors read and approved the final manuscript.

\section{Funding}

Open access funding provided by University of Gothenburg.

\section{Availability of data and materials}

Data openly available in a public repository that does not issue DOls. The data that support the findings of this study are openly available in the Humanitarian Data Exchange at https://data.humdata.org/dataset/novel-coronavirus2019-ncov-cases; The Humanitarian Data Exchange: Government of Nepal at https://covid19.ndrrma.gov.np/; Gobierno de México. Datos Abiertos-Dirección General de Epidemiología at: https://www.gob.mx/salud/documentos/ datos-abiertos-152127; Nigeria Centre for Disease Control at: https://covid19. ncdc.gov.ng/report/\#!; Instituto Nacional de Salud at https://infogram.com/ 1 pyg0lgpndvwweh3yx1exq1dq1uy6l7xmpg; Daegu Metropolitan City at: http://covid19.daegu.go.kr/; Variation in Government Responses to COVID-19 at: https://www.bsg.ox.ac.uk/research/research-projects/covid-19-gover nment-response-tracker. All accessed September 15, 2020.

\section{Declarations}

Ethics approval and consent to participate Not applicable.

\section{Consent for publication}

Not applicable.

\section{Competing interests}

The authors report no conflicts of interest.

\section{Author details}

${ }^{1}$ Department of Preventive Medicine, Kyung Hee University School of Medicine, Seoul, Korea. ${ }^{2}$ Global Health, School of Public Health and Community Medicine, Institute of Medicine, University of Gothenburg, Medicinaregatan 18A, 41390 Gothenburg, Sweden. ${ }^{3}$ Centre for Medicine and Society, AlbertLudwigs-University Freiburg, Bismarckallee (3'd floor), 79089 Freiburg, Germany. ${ }^{4}$ Laboratorio de Salud Pública, Instituto Departamental de Salud-IDS, Norte de Santander, Colombia. ${ }^{5}$ Grupo GIGA, Universidad Francisco de Paula Santander, San José de Cúcuta, Colombia. ${ }^{6}$ Angewandte Gesundheitswissenschaft, Ravensburg-Weingarten University, Weingarten, Germany. ${ }^{7}$ Present Address: Bangalore, India.

Received: 22 October 2020 Accepted: 22 September 2021

Published online: 02 October 2021

References

1. Mahato P, Tamang P, Simkhada P, et al. Effects of COVID-19 during lockdown in Nepal. Europasian J Med Sci. 2020. https://doi.org/10.46405/ ejms.v2i2.91.

2. Lancet T. India under COVID-19 lockdown. Lancet. 2020;395(10233):1315. https://doi.org/10.1016/S0140-6736(20)30938-7.

3. Ferguson NM, Laydon D, Nedjati-Gilani G, et al. Report 9: impact of nonpharmaceutical interventions (NPIs) to reduce COVID-19 mortality and healthcare demand. Imperial College COVID-19 Response Team. Imperial College London. 2020. https://doi.org/10.25561/77482.

4. Bargain O, Ulugbek A. Poverty and Covid-19 in developing countries. Poverty and Covid-19 in developing countries. Groupe de Recherche en Economie Théorique et Appliquée (GREThA), 2020.

5. Marques ES, Moraes CL, Hasselmann MH, Deslandes SF, Reichenheim ME Violence against women, children, and adolescents during the COVID-19 pandemic: overview, contributing factors, and mitigating measures. A violência contra mulheres, crianças e adolescentes em tempos de pandemia pela COVID-19: panorama, motivações e formas de enfrentamento. Cad Saude Publica. 2020;36(4):e00074420. https://doi.org/10. 1590/0102-311X00074420. 
6. Nadanovsky P, Santos APPD. Strategies to deal with the COVID-19 pandemic. Braz Oral Res. 2020;34: e068. https://doi.org/10.1590/1807-3107b or-2020.vol34.0068.

7. The Humanitarian Data Exchange. Novel Coronavirus (COVID-19) Cases Data. https://data.humdata.org/dataset/novel-coronavirus-2019-ncovcases. Accessed 15 July 2020.

8. The Humanitarian Data Exchange. Europe: Coronavirus (COVID-19) Subnational Cases. https://data.humdata.org/dataset/europe-covid-19subnational-cases/resource/6287f81b-0e07-43d7-babc-0017da056897. Accessed 15 July 2020.

9. Government of Nepal Ministry of Home Affairs National Disaster Risk Reduction and Mangement Authority. Nepal COVID-19 Dashboard. https://covid19.ndrrma.gov.np/.

10. Gobierno de México. Datos Abiertos-Dirección General de Epidemiología. https://www.gob.mx/salud/documentos/datos-abiertos-152127. Accessed 15 July 2020.

11. Nigeria Centre for Disease Control (NCDC). COVID-19 Nigeria. https:// covid19.ncdc.gov.ng/report/\#!. Accessed 15 July 2020.

12. Instituto Nacional de Salud. COVID-19 en personal de salud en Colombia. https://infogram.com/1 pyg0lgpndvwweh3yx1 exq1 dq1 uy617xmpg. Accessed 15 July 2020.

13. GoK Dashboard. Kerala: COVID-19 Battle. https://dashboard.kerala.gov.in/ index.php. Accessed 15 July 2020)

14. Daegu Metropolitan City. Daily COVID-19 related status. http://covid19. daegu.go.kr/. Accessed 15 Sept 2020.

15. United Nations Department of Economic and Social Affairs Population Dynamics. World Population Prospects 2019. https://population.un.org/ wpp/Download/Standard/Population/.

16. Hale T, Angrist N, Kira B, Petherick A, Phillips T, Webster S. Variation in Government Responses to COVID-19. Version 5.0. Blavatnik School of Government Working Paper. https://www.bsg.ox.ac.uk/research/publi cations/variation-government-responses-covid-19. Accessed 15 July 2020. https://doi.org/10.1371/journal.pmed1000097.

17. Hale T, Webster S, Petherick A, Phillips T, Kira B. Oxford COVID-19 Government Response Tracker. Blavatnik School of Government. Data use policy: Creative Commons Attribution CC BY standard. https://www.bsg.ox.ac. uk/research/research-projects/coronavirus-government-response-track er. Accessed 15 July 2020.

18. Google LLC. Google COVID-19 Community Mobility Reports. https:// www.google.com/covid19/mobility/. Accessed 5 July 2020.

19. Moher D, Liberati A, Tetzlaff J, Altman D. Preferred reporting items for systematic reviews and meta-analyses: the PRISMA statement. PLoS Med. 2009;6(7): e1000097. https://doi.org/10.1371/journal.pmed.1000097.

20. Bernal JL, Cummins S, Gasparrini A. Interrupted time series regression for the evaluation of public health interventions: a tutorial. Int J Epidemiol. 2017;46(1):348-55. https://doi.org/10.1093/ije/dyw098.

21. Sebastiani G, Massa M, Riboli E. Covid-19 epidemic in Italy: evolution, projections and impact of government measures. Eur J Epidemiol. 2020;35(4):341-5. https://doi.org/10.1007/s10654-020-00631-6.

22. Oksanen A, Kaakinen M, Latikka R, Savolainen I, Savela N, Koivula A. Regulation and trust: 3-month follow-up study on COVID-19 mortality in 25 European Countries. JMIR Public Health Surveill. 2020;6(2): e19218. https://doi.org/10.2196/19218.

23. Sjödin H, Wilder-Smith A, Osman S, Farooq Z, Rocklöv J. Only strict quarantine measures can curb the coronavirus disease (COVID-19) outbreak in Italy, 2020. Euro Surv. 2020;25(13):2000280. https://doi.org/10.2807/ 1560-7917.ES.2020.25.13.2000280.

24. Kim S, Seo YB, Jung E. Prediction of COVID-19 transmission dynamics using a mathematical model considering behavior changes in Korea. Epidemiol Health. 2020;42: e2020026. https://doi.org/10.4178/epih.e2020 026.

25. Choi SC, Ki M. Estimating the reproductive number and the outbreak size of novel coronavirus disease (COVID-19) using mathematical model in Republic of Korea. Epidemiol Health. 2020;42:e2020011.

26. Nussbaumer-Streit B, Mayr V, Dobrescu Al, et al. Quarantine alone or in combination with other public health measures to control COVID-19: a rapid review. Cochrane Database Syst Rev. 2020;4:CD013574. https://doi. org/10.1002/14651858.CD013574.

27. Burch J, Bunt C. What are the effects of quarantine plus other measures for controlling the spread of COVID-19? Cochrane Clin Answers. 2020. https://doi.org/10.1002/cca.3053.
28. de Bruin BY, Lequarre AS, McCourt J, et al. Initial impacts of global risk mitigation measures taken during the combatting of the COVID-19 pandemic. Saf Sci. 2020. https://doi.org/10.1016/j.ssci.2020.104773.

29. Gregori D, Azzolina D, Lanera C, et al. A first estimation of the impact of public health actions against COVID-19 in Veneto (Italy). J Epidemiol Commun Health. 2020. https://doi.org/10.1136/jech-2020-214209.

30. Signorelli C, Scognamiglio T, Odone A. COVID-19 in Italy: impact of containment measures and prevalence estimates of infection in the general population. Acta Biomed. 2020;91(3-S):175-9. https://doi.org/10.23750/ abm.v91i3-S.9511.

31. Ambikapathy B, Krishnamurthy K. Mathematical modelling to assess the impact of lockdown on COVID-19 transmission in India: model development and validation. JMIR Public Health Surveill. 2020;6(2): e19368. https://doi.org/10.2196/19368.

32. Manchein C, Brugnago EL, da Silva RM, Mendes CFO, Beims MW. Strong correlations between power-law growth of COVID-19 in four continents and the inefficiency of soft quarantine strategies. Chaos. 2020;30(4): 041102. https://doi.org/10.1063/5.0009454.

33. Shim E, Tariq A, Choi W, Lee Y, Chowell G. Transmission potential and severity of COVID-19 in South Korea. Int J Infect Dis. 2020;93:339-44. https://doi.org/10.1016/j.ijid.2020.03.031.

34. Tobías A. Evaluation of the lockdowns for the SARS-CoV-2 epidemic in Italy and Spain after one month follow up. Sci Total Environ. 2020;725: 138539. https://doi.org/10.1016/j.scitotenv.2020.13853.

35. Mandal S, Bhatnagar T, Arinaminpathy N, et al. Prudent public health intervention strategies to control the coronavirus disease 2019 transmission in India: a mathematical model-based approach. Indian J Med Res. 2020;151(2 \& 3):190-9. https://doi.org/10.4103/ijmr.IJMR_504_20.

36. Tomar A, Gupta N. Prediction for the spread of COVID-19 in India and effectiveness of preventive measures. Sci Total Environ. 2020;728: 138762. https://doi.org/10.1016/j.scitotenv.2020.138762.

37. Goldstein E, Lipsitch M. Temporal rise in the proportion of younger adults and older adolescents among coronavirus disease (COVID-19) cases following the introduction of physical distancing measures, Germany, March to April 2020. Euro Surveill. 2020. https://doi.org/10.2807/15607917.ES.2020.25.17.2000596.

38. COVID-19 National Emergency Response Center, Epidemiology and Case Management Team, Korea Centers for Disease Control and Prevention. Coronavirus Disease-19: The First 7,755 Cases in the Republic of Korea. Osong Public Health Res Perspect. 2020;11(2):85-90. https://doi.org/10. 24171/j.phrp.2020.11.2.05

39. Brauner JM, Mindermann S, Sharma M, et al. Inferring the effectiveness of government interventions against COVID-19. Science. 2020;371 (6531):eabd9338. https://doi.org/10.1126/science.abd9338.

40. Mitra A, Pakhare AP, Roy A, Joshi A. Impact of COVID-19 epidemic curtailment strategies in selected Indian states: an analysis by reproduction number and doubling time with incidence modelling. PLOS ONE. 2020;15(9): e0239026. https://doi.org/10.1371/journal.pone.0239026.

41. Rader B, Scarpino SV, Nande A, et al. Crowding and the shape of COVID19 epidemics. Nat Med. 2020;26:1829-34. https://doi.org/10.1038/ s41591-020-1104-0.

42. Worldometer. World Population Clock: 7.7 Billion People (2019)—Worldometers. https://www.worldometers.info/world-population/. Accessed 6 May 2021.

43. Barbieri DM, Lou B, Passavanti M, et al. Impact of COVID-19 pandemic on mobility in ten countries and associated perceived risk for all transport modes. PLoS ONE. 2021;16(2): e0245886. https://doi.org/10.1371/journal. pone. 0245886 .

44. Olufadewa II, Adesina MA, Ekpo MD, et al. Lessons from the coronavirus disease 2019 (COVID-19) pandemic response in China, Italy, and the U.S.: a guide for Africa and low- and middle-income countries. Global Health J. 2021;5(1):56-61. https://doi.org/10.1016/j.glohj.2021.02.003.

\section{Publisher's Note}

Springer Nature remains neutral with regard to jurisdictional claims in published maps and institutional affiliations. 